\title{
PENGEMBANGAN POTENSI HASIL HUTAN BUKAN KAYU OLEH KELOMPOK SADAR HUTAN LESTARI WANA AGUNG DI REGISTER 22 WAY WAYA KABUPATEN LAMPUNG TENGAH
}

\section{(THE DEVELOPMENT PLAN OF NON-TIMBER FOREST PRODUCTS POTENTIAL BY SADAR HUTAN LESTARI WANA AGUNG GROUPS AT REGISTER 22 WAY WAYA LAMPUNG TENGAH REGENCY)}

\author{
Desi Indrasari, Christine Wulandari, Afif Bintoro \\ Jurusan Kehutanan Fakultas Pertanian Universitas Lampung \\ J1. Soemantri Brojonegoro No. 1 Bandar Lampung 35145 \\ Email : cii.indra.ci@gmail.com
}

\begin{abstract}
ABSTRAK
Pemanfaatan hasil hutan untuk menyejahterakan masyarakat desa sekitar hutan harus tetap dijaga kelestariannya. Adanya pengembangan HHBK diharapkan mampu meningkatkan keanekaragaman hasil hutan yang dapat dimanfaatkan. Penelitian bertujuan untuk menganalisis faktor-faktor yang berpengaruh terhadap pengembangan potensi HHBK oleh Kashuri Wana Agung. Penelitian dilakukan pada bulan Oktober 2015 di Desa Sendang Asri dan Sendang Mukti, Kabupaten Lampung Tengah. Penelitian menggunakan metode teknik observasi dan wawancara dengan kuesioner, kemudian dianalisis menggunakan SWOT. Hasil penelitian menunjukkan HHBK yang berpotensi dikembangkan yaitu petai (Parkia speciosa), pinang (Areca catechu), alpukat (Persea gratissima), jengkol (Pithecellobium lobatum), dan aren (Arenga pinnata). Faktor-faktor yang berpengaruh dalam pengembangan HHBK yaitu luas lahan, kreativitas Kashuri, dan harga pasar. Berdasarkan matriks SWOT diketahui bahwa pengembangan potensi HHBK dapat dilakukan dengan adanya dukungan pemerintah dan pihak terkait (LSM dan Kashuri) berupa pemberian penyuluhan dan pelatihan untuk meningkatkan kreativitas Kashuri Wana Agung dalam mengelola, mengolah dan memasarkan produk HHBK.
\end{abstract}

Kata Kunci : Kashuri, Potensi HHBK, SWOT

\section{ABSTRACT}

The utilization of forest products for the welfare of rural communities surroundings the forest must be maintained its sustainability. The development of NTFP was expected to increase the diversity of forest products. Research was aimed to analyze the factors that affecting the potential development of NTFPs by Kashuri Wana Agung. This research was conducted in October 2015 at Sendang Asri and Sendang Mukti villages, Lampung Tengah regency. Research was using observation and interviews method with questionnaires, and analyzed using SWOT. The result showed that the potential NTFPs in Wana Agung namely petai (Parkia speciosa), pinang (Areca catechu), alpukat (Persea gratissima), jengkol (Pithecellobium lobatum), and aren (Arenga pinnata). Factors to affecting the development of NTFP namely limited area, Kashuri's creativity, and the market price. Based on SWOTs matrix, NTFPs development can be done by supporting of government and related parties (NGOs and Kashuri's). The support can be in extention education and training to develop Kashuri Wana Agung creativity to manage, process, and market the NTFPs product.

Key word : Kashuri, NTFP potential, SWOT 


\section{PENDAHULUAN}

Register 22 Way Waya merupakan kawasan hutan lindung yang termasuk dalam wilayah Kabupaten Lampung Tengah. Menurut Watala (2009), sejak bergulir era reformasi banyak masyarakat yang melakukan perambahan untuk mendapatkan lahan garapan, kondisi tersebut mengakibatkan hampir seluruh kawasan hutan di Kabupaten Lampung Tengah rusak. Kerusakan kawasan hutan tersebut berdampak pada masyarakat desa yang ada di sekitar kawasan sehingga mereka sadar akan pentingnya keberadaan hutan.

Kelompok sadar hutan lestari (Kashuri) Wana Agung merupakan kelompok masyarakat gabungan dari desa Sendang Asri dan Sendang Mukti yang keduanya merupakan desa yang berada di sekitar Register 22 Way Waya. Adanya kesadaran untuk menjaga kelestarian hutan menjadi awal mula terbentuknya Kashuri. Upaya menjaga kelestarian hutan yang diikuti dengan pemanfaatan sumberdaya alam secara bijaksana oleh masyarakat dapat memberikan penghidupan yang baik bagi mereka. Hal ini sejalan dengan pernyataan Susilowati (2007), bahwa perlibatan masyarakat juga dinilai telah menggeser paradigma pengelolaan hutan yang berbasis hasil kayu (timber management) ke pengelolaan yang berbasis sumberdaya (resource management) yang mengedepankan pengelolaan sumberdaya hutan partisipatif.

Kashuri Wana Agung saat ini sedang dalam proses pengajuan izin HKm (Hutan Kemasyarakatan). Saat ini Kashuri Wana Agung telah memiliki izin Pencadangan Areal HKm (PAK), hanya saja sedang dalam proses persetujuan izin Pengelolaan dari pemerintah daerah setempat. Diperkirakan izin Pengelolaan tersebut akan disetujui pada tahun 2016. Izin dari pemerintah secara resmi diperlukan oleh Kashuri Wana Agung untuk mendapatkan legalitas dalam mengelola kawasan hutan. Menurut Nurrani dan Tabba (2013) tingginya nilai dan manfaat hutan bagi masyarakat berimplikasi pada ketergantungan masyarakat terhadap hasil hutan kayu, hasil hutan bukan kayu dan satwa liar.

Kelebihan pemanfaatan HHBK (Hasil Hutan Bukan Kayu) dapat membantu masyarakat mendapatkan sumber mata pencaharian yang lebih beragam tanpa merusak hutan. Hal tersebut seperti diungkapkan Irawanti, Suka, dan Ekawati (2012), bahwa dengan menanam berbagai jenis tanaman buah-buahan dan tanaman perkebunan, petani dapat memenuhi seluruh kebutuhan jangka pendek, jangka menengah dan jangka panjang. Namun kecukupannya sangat dipengaruhi oleh luasan lahannya. Jangka waktu panen HHBK yang lebih singkat sangat besar peranannya dalam mempertahankan eksistensi hutan karena petani tetap mempunyai sumber pendapatan dari lahan hutan. Selain itu, juga dapat memberikan pengetahuan kepada masyarakat lokal, bahwa pemanfaatan hutan tidak hanya dari kayunya saja, melainkan dengan pemanfaatan buah-buahan seperti durian, mangga, alpukat, serta hasil hutan lainnya seperti karet, atau rotan dan lain sebagainya.

Pemanfaatan HHBK yang lebih optimal didapatkan dengan jenis HHBK yang lebih beragam, sehingga akan lebih banyak produk yang dapat dipasarkan. Hasil agroforestri di suatu wilayah yang didiversifikasi akan meningkatkan macam produk yang akan dipasarkan, sehingga diharapkan dapat menunjang perekonomian masyarakat pedesaan (Wulandari, 2013). Penelitian bertujuan untuk menganalisis faktor-faktor yang berpengaruh terhadap pengembangan potensi HHBK oleh Kashuri Wana Agung di Register 22 Way Waya Kabupaten Lampung Tengah.

\section{METODE PENELITIAN}

\section{Lokasi dan Waktu Penelitian}

Penelitian ini dilakukan di Desa Sendang Asri dan Desa Sendang Mukti pada 3 kelompok yang tergabung dalam Kashuri Wana Agung yaitu kelompok Sari Aji, Karya Bhakti dan Sido Makmur, Kecamatan Sendang Agung, Kabupaten Lampung Tengah pada bulan Oktober 2015. 


\section{Data yang Dikumpulkan}

Data yang dikumpulkan merupakan data primer dan data sekunder. Data primer yang dimaksud yaitu sikap, minat, perilaku dan pengetahuan anggota Kashuri Wana Agung mengenai HHBK yang dapat dimanfaatkan. Pengambilan data dilakukan dengan teknik observasi, wawancara, dan studi pustaka.

Pengambilan sampel kelompok tani dilakukan secara purposive sampling. Berdasarkan data sekunder jumlah anggota Kashuri Wana Agung yaitu 172 orang yang memiliki luas lahan 70,45 ha. Jumlah responden diperoleh menggunakan formula Slovin (1960) dalam Arikunto (2010) yaitu

$$
\mathrm{n}=\frac{N}{N\left(e^{2}\right)+1}
$$

Keterangan :

$\mathrm{n}=$ jumlah sampel responden yang dambil dalam penelitian

$\mathrm{N}=$ jumlah populasi petani anggota kelompok yang ada di lokasi penelitian

$\mathrm{e}=$ presisi/batas eror $(10 \%)$

$1=$ bilangan konstanta

Jadi, jumlah responden yang diambil pada Kashuri Wana Agung adalah 63 responden. Jumlah responden dalam masing-masing sub kelompok yaitu :

- Kelompok Sari Aji $=\frac{5}{1} \times 63=18,68=19$ responden

- Kelompok Sido Makmur $=\frac{7}{1}$ x $63=25,64=25$ responden

- Kelompok Karya Bhakti $=\frac{5}{1} \times 63=18,68=19$ responden

\section{Analisis Data}

Pengolahan data dilakukan dengan metode analisis SWOT. Menurut Rangkuti (2014) analisis SWOT adalah salah satu metode yang ditetapkan dengan tujuan untuk mengidentifikasi berbagai faktor (internal dan eksternal) secara sistematis untuk menentukan strategi suatu kegiatan. Analisis internal meliputi penilaian terhadap faktor kekuatan (Strength) dan kelemahan (Weakness). Sementara, analisis eksternal mencakup faktor peluang (Opportunity) dan tantangan (Threaths). Berdasarkan hasil pengolahan data menggunakan SWOT yang menghasilkan 4 alternatif strategi, kemudian disimpulkan berdasarkan alternatif dominan dalam matriks SWOT tersebut. Analisis data dilakukan dengan analisis deskriptif kualitatif. Menggunakan metode deskriptif dengan tujuan untuk membuat deskripsi, gambaran umum atau lukisan secara sistematis, faktual dan akurat mengenai fakta-fakta, sifat-sifat serta hubungan antar fenomena yang diselidiki (Nazir, 2005). Data mengenai jenis-jenis produk HHBK yang telah didapatkan dari hasil survai dan studi literatur disusun dalam bentuk tabel, kemudian dianalisis secara deskriptif.

\section{HASIL DAN PEMBAHASAN}

\section{Karakteristik Responden}

Responden penelitian ini memiliki rentang usia antara 25 - 70 tahun. Kategori usia antara 30 - 40 tahun merupakan usia yang paling mendominasi. Responden penelitian ini merupakan petani padi, petani karet dan buruh tani. Pendapatan rata-rata responden memiliki rentang antara $<\mathrm{Rp} 500.000$ hingga $>\mathrm{Rp} 2.000 .000$, dengan dominasi pendapatan rata-rata responden yaitu antara Rp500.000 - Rp1.000.000. Tingkat pendidikan responden penelitian ini terdiri dari 2 kategori yaitu Pendidikan Dasar (SD dan SMP) dan Pendidikan Menengah (SMA/SMK). Berdasarkan data hasil kuisioner, tingkat pendidikan responden didominasi 
dengan kategori pendidikan dasar yaitu pada tingkat SD. Persentase tingkat pendidikan terbesar adalah SD yaitu 64\%, kemudian SMP yaitu 22\%, dan SMA yaitu $14 \%$.

Berdasarkan hasil penelitian dapat diketahui jumlah jenis tanaman pada masing-masing lahan usulan areal HKm anggota Kashuri Wana Agung dapat dilihat pada tabel 1 berikut.

Tabel 1. Jumlah tanaman MPTS di lahan usulan HKm anggota Kashuri Wana Agung.

\begin{tabular}{rllrrr}
\hline No & $\begin{array}{c}\text { Nama } \\
\text { lokal }\end{array}$ & \multicolumn{1}{c}{ Nama Ilmiah } & $\begin{array}{c}\text { Petani } \\
\text { (orang) }\end{array}$ & $\begin{array}{c}\text { Jumlah } \\
\text { Tanaman } \\
\text { (batang) }\end{array}$ & $\begin{array}{c}\text { Prediksi harga } \\
\text { (Rp/kg) }\end{array}$ \\
\hline $\mathbf{1}$ & Kakao & Theobroma cacao & 49 & 7.354 & 13.000 \\
$\mathbf{2}$ & Karet & Hevea brasiliensis & 63 & 7.047 & 6.000 \\
$\mathbf{3}$ & Petai & Parkia speciosa & 54 & 997 & $20.000^{(1)}$ \\
$\mathbf{4}$ & Pinang & Areca catechu & 32 & 550 & 8.000 \\
$\mathbf{5}$ & Tangkil & Gnetum gnemon & 15 & 233 & 30.000 \\
$\mathbf{6}$ & Kopi & Coffea sp. & 5 & 220 & $20.000^{(2)}$ \\
$\mathbf{7}$ & Durian & Durio zibethinus & 35 & 196 & $25.000^{(3)}$ \\
$\mathbf{8}$ & Kemiri & Aleurites moluccana & 25 & 159 & 24.000 \\
$\mathbf{9}$ & Alpukat & Persea gratissima & 11 & 135 & 20.000 \\
$\mathbf{1 0}$ & Jengkol & Pithecellobium lobatum & 27 & 125 & 25.000 \\
$\mathbf{1 1}$ & Nangka & Artocarpus heterophyllus & 15 & 81 & $2.000^{(3)}$ \\
$\mathbf{1 2}$ & Aren & Arenga pinnata & 7 & 49 & 3.000 \\
$\mathbf{1 3}$ & Mangga & Mangifera indica & 5 & 27 & 10.000 \\
$\mathbf{1 4}$ & Lada & Piper nigrum & 2 & 7 & 200.000 \\
$\mathbf{1 5}$ & Kapuk & Ceiba pentandra & 1 & 4 & 25.000 \\
$\mathbf{1 6}$ & Pisang & Musa paradisiaca & 1 & 3 & $15.000^{(4)}$ \\
$\mathbf{1 7}$ & Cengkih & Eugenia aromaticum & 1 & 2 & 115.000 \\
\hline
\end{tabular}

Sumber : Data Primer Olahan (2015)

Keterangan :

*Jumlah petani yang memiliki tanaman MPTS

${ }^{(1}$ Harga petai per empong (satu ikat besar)

${ }^{(2}$ Harga kopi berupa kopi bubuk

${ }^{(3}$ Harga durian dan nangka per buah

${ }^{(4}$ Harga pisang per sisir

Dua jenis tanaman yang mendominasi pada lahan Kashuri Wana Agung yaitu tanaman kakao dan karet. Hal tersebut dikarenakan tanaman lain yang mati sebelum berbuah. HHBK yang mendominasi saat ini adalah getah karet hasil sadapan yang dijual ke pengepul atau ke tengkulak. HHBK berupa buah-buahan masih dimanfaatkan untuk konsumsi pribadi. Hal tersebut dikarenakan hasil yang didapat terlalu sedikit sehingga tidak memungkinkan untuk dipasarkan. Berdasarkan data pada tabel 1 dapat diketahui bahwa terdapat 5 jenis HHBK dari 12 jenis HHBK lainnya yang memiliki potensi untuk dikembangkan. Kelima jenis tersebut yaitu petai, pinang, alpukat, jengkol, dan aren. Berdasarkan jumlah hasil panen yang didapatkan dari kelima jenis tanaman tersebut memiliki potensi untuk dikembangkan oleh Kashuri Wana Agung. Jumlah hasil panen dari masing-masing jenis berbeda-beda yaitu kakao sebesar $40 \mathrm{~kg}$, getah karet sebesar $50 \mathrm{~kg}-1 \mathrm{kwintal}$, petai sebesar 3 empong, pinang sebesar $50 \mathrm{~kg}$, alpukat sebesar 10 - $20 \mathrm{~kg}$, jengkol sebesar $1 \mathrm{kwintal}$ dan aren sebesar $30-50$ kg. Selain hasil panen yang memungkinkan untuk dipasarkan kelima jenis tanaman tersebut juga merupakan jenis buah yang biasa dikonsumsi masyarakat. Delapan jenis HHBK lainnya yang tidak berpotensi disebabkan oleh pohon yang rawan roboh. Jenis tanaman yang semakin berkurang bahkan sudah tidak ada lagi di lahan Kashuri Wana Agung seperti kopi dan pisang. Serta, hasil yang tidak dapat dipanen baik disebabkan oleh buah yang habis diambil warga maupun disebabkan oleh tanaman yang tidak berbuah. 


\section{Hasil Wawancara dengan Kashuri Wana Agung dalam Mengelola dan Mengembangkan Potensi HHBK}

\section{Pengetahuan Kashuri Wana Agung}

Berdasarkan hasil penelitian diketahui bahwa sebanyak $60 \%$ responden mengetahui pengertian HHBK dan $40 \%$ responden tidak mengetahui pengertian HHBK. Persentase tersebut diasumsikan bahwa sebagian besar responden telah mengetahui pengertian dan jenisjenis HHBK yang dapat dimanfaatkan. Sebagian responden lainnya diasumsikan tidak mengetahui pengertian dari HHBK, tetapi mampu menyebutkan jenis-jenis HHBK.

Perbedaan persentase tersebut disebabkan perbedaan informasi masing-masing anggota Kashuri Wana Agung. Anggota Kashuri yang mengetahui pengertian HHBK merupakan anggota yang aktif atau pernah mengikuti penyuluhan maupun pelatihan mengenai HHBK. Anggota Kashuri yang tidak mengetahui pengertian HHBK merupakan anggota yang belum pernah mengikuti penyuluhan maupun pelatihan mengenai HHBK. Anggota yang tidak mengikuti penyuluhan maupun pelatihan dikarenakan tidak diundang, karena anggota yang diundang hanya beberapa orang sebagai perwakilan.

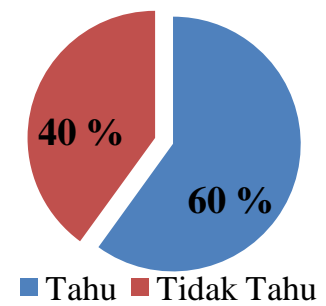

Gambar 1. Tingkat pengetahuan anggota Kashuri Wana Agung mengenai HHBK.

\section{Minat Kashuri Wana Agung}

Berdasarkan hasil penelitian, anggota Kashuri Wana Agung memiliki minat tinggi dalam menanam tanaman MPTS selain karet dan kakao. Persentase minat anggota Kashuri dalam mengembangkan jenis HHBK yaitu $82 \%$ responden yang berminat dan $18 \%$ responden yang tidak berminat. Menurut Suharyat (2009), minat merupakan suatu kecenderungan untuk bertindak terhadap suatu situasi atau melakukan aktivitas yang menjadi objek dari minat tersebut disertai rasa senang. Anggota Kashuri Wana Agung yang berminat mengembangkan HHBK dikarenakan adanya keinginan meningkatkan keanekaragaman jenis HHBK yang dapat dimanfaatkan sehingga diharapkan dapat meningkatkan pendapatan mereka. Tingginya minat Kashuri akan berpengaruh terhadap pengembangan potensi HHBK, karena mereka akan memiliki kecenderungan dalam melakukan upaya-upaya untuk meningkatkan HHBK di lahan mereka.

Akan tetapi, terdapat kendala dalam upaya pengembangan HHBK, di antaranya $43 \%$ responden mengalami kurangnya modal untuk menambah bibit dan membeli pupuk, 15\% kurang bibit yang berkualitas, 3\% tukulan dicuri oleh warga dari daerah lain, 15\% tanaman mati setelah ditanam, 18\% kurangnya lahan, 3\% kurangnya informasi mengenai jenis HHBK dan 3\% harga jual rendah. Hal tersebut di atas, menyebabkan penurunan minat Kashuri untuk mengembangkan HHBK.

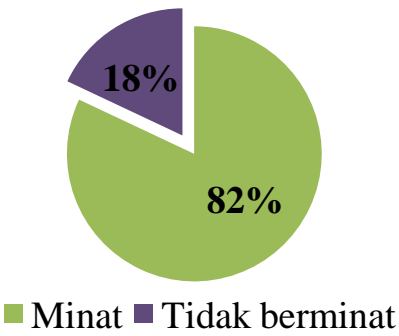

Gambar 2. Minat Anggota Kasnurı wana Agung dalam mengembangkan potensi HHBK. 


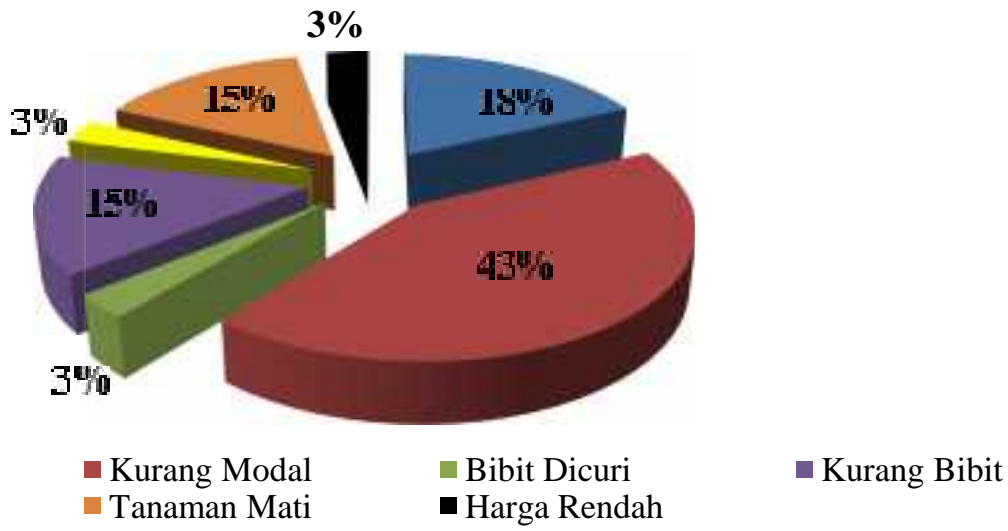

Gambar 3. Kendala yang dialami Kashuri Wana Agung dalam menngembangkan HHBK.

\section{Sikap Kashuri Wana Agung}

Sikap merupakan respon dari seseorang terhadap suatu kegiatan yang ada. Menurut (Suharyat, 2009) sikap adalah suatu sistem evaluasi positif atau negatif, yakni suatu kecenderungan untuk menyetujui atau menolak. Berdasarkan data kuisioner diketahui bahwa anggota Kashuri Wana Agung memiliki sikap positif terhadap pengembangan potensi HHBK. Adanya minat tinggi Kashuri Wana Agung menimbulkan sikap positif dalam mengembangkan potensi HHBK. Perasaan merupakan salah satu faktor psikis yang memperngaruhi minat, perasaan senang akan menimbulkan minat yang akan diperkuat adanya sikap positif sebab perasaan senang merupakan suatu keadaan jiwa akibat adanya peristiwa yang datang pada subyek bersangkutan (Wulandari, 2012). Sikap positif Kashuri terlihat dari kegiatan yang diterapkan untuk mengembangkan HHBK yang dapat dilihat pada gambar 5 . Sikap positif tersebut berdasarkan persentase anggota Kashuri yang setuju terhadap pengembangan potensi HHBK sebesar $86 \%$, sedangkan Kashuri yang tidak setuju yaitu $14 \%$. Anggota Kashuri yang tidak setuju terhadap pengembangan potensi HHBK dikarenakan kurangnya lahan dan tanaman yang sulit tumbuh. Kurangnya lahan menyebabkan Kashuri Wana Agung tidak dapat menambah tanaman MPTS lainnya.

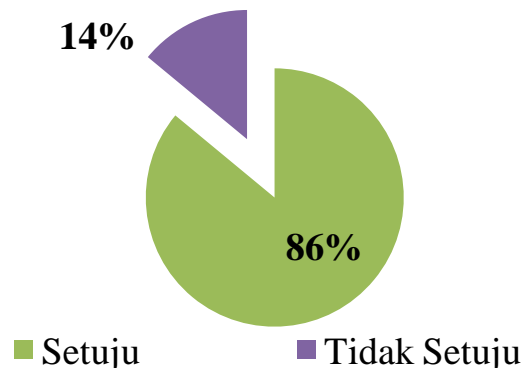

Gambar 4. Sikap Anggota Kashuri Wana Agung dalam mengembangkan potensi HHBK.

\section{Perilaku Kashuri Wana Agung}

Menurut Notoatmodjo (2003) perilaku merupakan kegiatan atau aktivitas manusia, baik yang diamati langsung maupun tidak dapat diamati pihak luar. Berdasarkan hasil penelitian diketahui sebanyak $78 \%$ responden memanfaatkan bibit karet yang tumbuh secara alami (tukulan) dan sebanyak 22\% responden membuat kebun bibit. Kedua kegiatan tersebut dilakukan agar masyarakat dapat memanfaatkan bibit untuk menyulam lahan mereka. Keberadaan tukulan dan kebun bibit dapat meminimalisir dana penyulaman. Selain itu, 
tukulan yang terawat dapat dijual sehingga menambah dana untuk membeli benih tanaman MPTS atau tanaman berkayu yang diletakkan di kebun bibit Kashuri Wana Agung.

Berdasarkan hasil penelitian dapat diketahui sebanyak 33\% responden tidak melakukan upaya dalam pengembangan HHBK, karena mereka kekurangan modal untuk membeli bibit MPTS yang berkualitas. Responden yang mengisi lahan kosong untuk ditanami tanaman MPTS maupun tanaman berkayu sebanyak 25\%, karena mereka ingin memanfaatkan lahan dengan optimal. Sebesar 22\% responden mengajak anggota Kashuri lainnya menanam tanaman MPTS dan 11\% responden melakukan diskusi kelompok. Hal tersebut dilakukan agar mereka dapat saling bertukar informasi mengenai jenis tanaman yang dapat tumbuh dan dimanfaatkan hasilnya. Terdapat 5\% responden menanam tanaman MPTS dengan jenis yang berbeda dari yang sudah ada di lahan mereka. Hal tersebut dilakukan dengan tujuan untuk memperoleh HHBK yang lebih beragam di lahan mereka. Responden yang melakukan 3 upaya (menanam tanaman berkayu, melakukan diskusi dengan kelompok dan mengajak anggota Kashuri lainnya untuk menanam tanaman MPTS) dalam pengembangan HHBK yaitu sebesar $3 \%$.

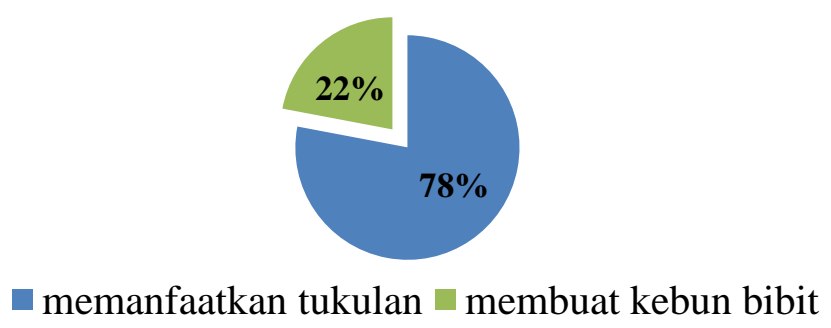

Gambar 5. Kegiatan yang diterapkan dalam pengembangan potensi HHBK oleh anggota Kashuri Wana Agung.

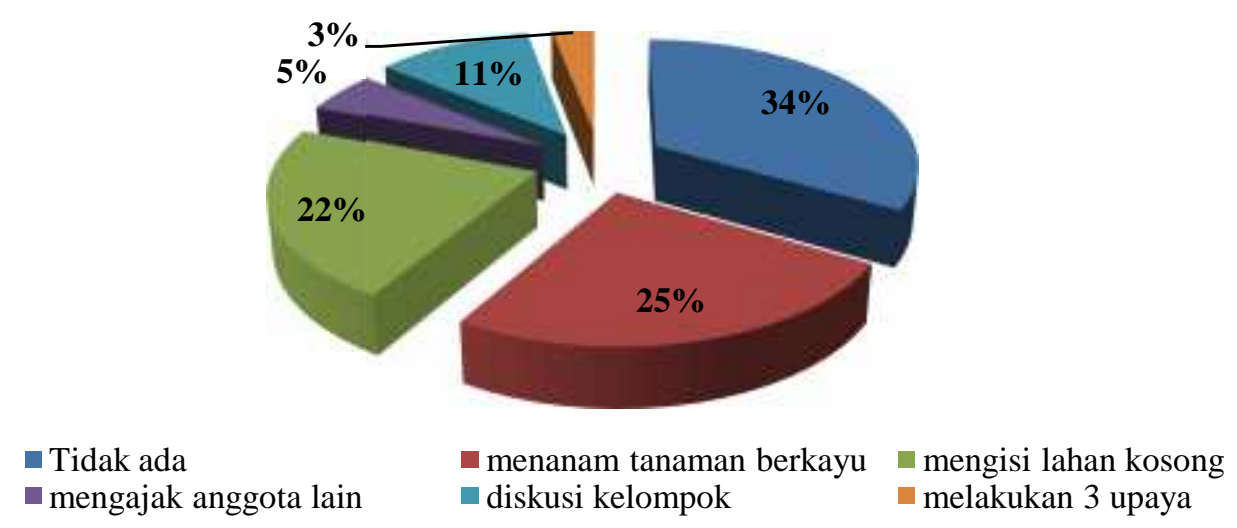

Gambar 6. Upaya pengembangan potensi HHBK oleh anggota Kashuri Wana Agung.

\section{Analisis Pengembangan Potensi HHBK di Register 22 Way Waya}

Strategi pengembangan potensi HHBK di Register 22 Way Waya dapat dilakukan dengan mengidentifikasi faktor internal dan eksternal menggunakan matriks SWOT berikut. 
Tabel 2. Matriks SWOT Pengembangan Potensi HHBK.

\begin{tabular}{|c|c|c|}
\hline IFAS & 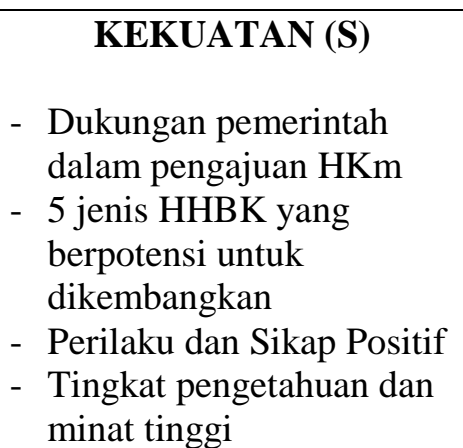 & $\begin{aligned} & \text { KELEMAHAN }(\mathbf{W}) \\
& \\
& \text { - } \text { Aksesbilitas kurang } \\
& \text { - } \text { Kreativitas rendah } \\
& \text { - } \text { Komposisi tanaman } \\
& \text { dominan jenis tanaman } \\
& \text { karet dan kakao } \\
& \text { - Pemanfaatan lahan kurang } \\
& \text { - Kurang modal }\end{aligned}$ \\
\hline $\begin{array}{l}\quad \text { PELUANG (O) } \\
\text { - } \text { Komitmen tinggi dari Dinas } \\
\text { Kehutanan untuk } \\
\text { memperjelas status HKm } \\
\text { - } \text { Adanya peraturan daerah } \\
\text { - } \text { Izin Pencadangan Areal } \\
\text { HKm yang sudah diberikan } \\
\text { dari Kementrian } \\
\text { - } \text { Keragaman jenis HHBK } \\
\text { yang dimanfaatkan tinggi }\end{array}$ & $\begin{array}{l}\text { STRATEGI S-O } \\
\text { - Pemberian bantuan dalam } \\
\text { proses IUPHKm } \\
\text { - Peningkatan kualitas } \\
\text { HHBK yang berpotensi } \\
\text { - Penambahan } \\
\text { keaneragaman jenis } \\
\text { tanaman yang } \\
\text { menghasilkan HHBK }\end{array}$ & $\begin{array}{l}\text { STRATEGI W-O } \\
\\
\text { - Perbaikan akses oleh } \\
\text { pemerintah setempat } \\
\text { - Peningkatan kreativitas } \\
\text { dalam memanfaatkan } \\
\text { HHBK } \\
\text { - Pemanfaatan lahan yang } \\
\text { lebih maksimal dengan } \\
\text { menanam bibit pada lahan } \\
\text { mereka }\end{array}$ \\
\hline $\begin{array}{l}\quad \text { ANCAMAN (T) } \\
\text { - Pencurian bibit } \\
\text { - Minimnya pelatihan kepada } \\
\text { Kashuri } \\
\text { - Harga jual relatif rendah }\end{array}$ & \begin{tabular}{l}
\multicolumn{1}{c}{ STRATEGI S-T } \\
- Pelatihan pembibitan karet \\
dengan kualitas yang lebih \\
baik \\
- Fasilitas pengadaan \\
kegiatan berkumpul \\
anggota Kashuri Wana \\
Agung untuk saling \\
memberikan informasi dan \\
pengetahuan
\end{tabular} & $\begin{array}{l}\text { STRATEGIW-T } \\
\text { - Peningkatan sumberdaya } \\
\text { manusia (SDM) } \\
\text { - Mediator untuk } \\
\text { pengembangan produk } \\
\text { HHBK }\end{array}$ \\
\hline
\end{tabular}

\section{Strategi Strength-Opportunity (SO)}

Adanya dukungan dari pemerintah berupa pemantauan proses Izin Usaha Pengelolaan Hutan Kemasyarakatan (IUPHKm) diikuti jenis HHBK yang memiliki jumlah tinggi pada lahan Kashuri Wana Agung yang dapat dipasarkan berupa petai, pinang, alpukat, jengkol, dan aren, perilaku dan sikap positif, serta tingkat pengetahuan dan minat yang tinggi merupakan kekuatan yang dimiliki oleh Kashuri Wana Agung untuk mengembangkan HHBK.

Adanya komitmen tinggi dari Dinas Kehutanan dan Perkebunan (Dishutbun) Kabupaten Lampung Tengah untuk memperjelas status HKm dari Kashuri diikuti Kebijakan dalam Peraturan Daerah Kabupaten Lampung Tengah No. 1 tahun 2012 Tentang Rencana Tata Ruang Wilayah Kabupaten Lampung Tengah Tahun 2011-2031 dan izin Pencadangan Areal (PAK) yang telah dimiliki oleh Kashuri merupakan peluang yang dimiliki Kashuri Wana Agung. Izin Pencadangan Areal (PAK) tersebut memberikan harapan bagi Kashuri Wana Agung untuk mendapatkan IUPHKm sebagai syarat legalitas dalam mengelola kawasan hutan.

Strategi yang menggunakan kekuatan untuk memanfaatkan peluang yaitu pemanfaatan faktor kekuatan dan peluang sehingga dapat membantu proses perijinan $\mathrm{HKm}$ untuk mendapatkan IUPHKm. Legalitas yang didapatkan membantu Kashuri dalam pengembangan HHBK dengan mengajukan kerja sama dengan suatu instansi atau lembaga tertentu. Kerja 
sama tersebut dapat berupa pemberian penyuluhan mengenai $\mathrm{HKm}$ dan produk-produk HHBK, dengan meningkatkan jumlah jenis tanaman yang memiliki potensi untuk dikembangkan, dengan bantuan bibit berkualitas sehingga dapat meningkatkan keragaman jenis HHBK sehingga secara langsung meningkatkan pendapatan anggota Kashuri Wana Agung. Selain itu juga, dilakukan peningkatan kualitas tanaman sehingga hasil panen akan meningkat. Serta dengan pengolahan hasil panen yang lebih beragam sehingga akan menambah nilai produk HHBK yang akan dipasarkan. Menurut Supadi dan Nurmanaf (2006) diversifikasi horizontal berupa menganekaragamkan jenis tanaman untuk mengefisienkan penggunaan lahan sehingga mampu meningkatkan ketahanan ekonomi rumah tangga dan keberlanjutan usaha sedangkan diversifikasi vertikal dalam bentuk penganekaragaman produk dapat dilakukan oleh pengusaha dan petani dalam upaya meningkatkan nilai tambah.

\section{Strategi Strength-Threat (ST)}

Pencurian bibit (tukulan) merupakan ancaman dalam pengembangan potensi HHBK. Strategi yang menggunakan kekuatan untuk menghindari ancaman dalam pengembangan potensi HHBK yaitu dengan adanya pelatihan pembibitan karet dengan kualitas yang lebih baik dan mengadakan kegiatan diskusi antar anggota yang lebih intensif untuk saling berbagi informasi dan pengetahuan sehingga diharapkan dapat memberikan solusi terhadap kendala yang dialami dalam mengembangkan potensi HHBK.

\section{Strategi Weakness-Opporrtunity (WO)}

Rendahnya kreativitas dari Kashuri Wana Agung, komposisi jenis tanaman yang didominasi karet dan kakao, kurangnya pemanfaatan lahan dan aksesbilitas buruk merupakan kelemahan dari pengembangan HHBK di lokasi penelitian. Kreativitas dalam pemanfaatan HHBK dapat membantu mereka untuk memasarkan produk yang lebih beragam dan dapat meningkatkan harga jual.

Strategi yang memanfaatkan peluang untuk mengatasi kelemahan yaitu bantuan bibit berkualitas dari pemerintah dapat dimanfaatkan oleh Kashuri Wana Agung untuk memanfaatkan lahan lebih maksimal. Penyuluhan dan pelatihan pihak terkait dilakukan untuk meningkatkan kreativitas dalam memanfaatkan lahan dan perawatan tanaman. Menurut Sudirman dalam Waluyo dan Sari (2014) pelaksanaan pelatihan juga dapat saja dilakukan di masyarakat, yang juga bertujuan untuk meningkatkan kualitas dari warga masyarakat seperti pengetahuan atau bidang keterampilan tertentu. Perbaikan akses untuk mempermudah pihakpihak terkait menuju kedua desa tersebut.

\section{Strategi Weakness-Threat (WT)}

Kurangnya modal merupakan salah satu kelemahan pengembangan potensi HHBK. Harga jual rendah dan minimnya pelatihan kepada Kashuri merupakan ancaman pengembangan potensi HHBK. Strategi yang meminimalkan kelemahan dan menghindari ancaman dalam mengembangkan potensi HHBK yaitu peningkatan SDM melalui pelatihan dari pihak terkait. Pihak terkait sebagai mediator pengembangan produk HHBK dan pangsa pasar.

\section{Strategi Pengembangan HHBK}

Dukungan dari pemerintah dan pihak instansi terkait merupakan hal penting dalam pengembangan potensi HHBK mulai dari proses perijinan IUPHKm sehingga dapat melakukan kerjasama berupa penyuluhan, pelatihan hingga penyediaan bibit berkualitas. Kegiatan tersebut dapat meningkatkan kreativitas Kashuri dalam memanfaatkan lahan dan merawat tanaman sehingga tanaman di lahan mereka lebih beragam yang diharapkan meningkatkan pendapatan Kashuri Wana Agung. 
Pemanfaatan lahan oleh Kashuri Wana Agung dapat dilakukan dengan memberdayakan lahan di sela-sela tanaman lainnya dengan sistem agroforestri. Menurut Njurumana dan Butarbutar (2008) potensi sumberdaya lahan yang tersedia dengan daya adaptasi alamiah untuk jenis tanaman hasil hutan bukan kayu dapat dikembangkan dengan model pendekatan agroforestri berbasis HHBK yang merupakan terobosan alternatif dalam pemanfaatan satuan unit lahan secara intensif dalam rangka meningkatkan produktivitas dan kualitas produksi sehingga dapat meningkatkan diversifikasi pendapatan masyarakat pedesaan. Sistem agroforestri dapat diterapkan oleh Kashuri Wana Agung dengan menanam tumbuhan bawah. Tumbuhan yang dapat digunakan antara lain jenis empon-empon (tanaman rimpang/rempahrempah) seperti kunyit, jahe, kencur, lengkuas, kapulaga dan lain-lain. Menurut Irawanti dkk (2012) pemilikan lahan oleh petani relatif sempit sehingga pembangunan HKm direkomendasikan menggunakan teknik agroforestri atau campuran tanaman kehutanan dengan berbagai jenis tanaman semusim, empon-empon, tanaman hijauan pakan ternak, tanaman perkebunan dan tanaman buah-buahan yang dapat menghasilkan berbagai jenis HHBK.

\section{SIMPULAN}

Berdasarkan penelitian yang telah dilakukan dapat disimpulkan bahwa :

1. Jenis HHBK yang memiliki potensi untuk dikembangkan oleh Kashuri Wana Agung yaitu petai (Parkia speciosa), pinang (Areca catechu), alpukat (Persea gratissima), jengkol (Pithecellobium lobatum), dan aren (Arenga pinnata).

2. Faktor-faktor yang berpengaruh dalam pengembangan HHBK yaitu luas lahan, kreativitas Kashuri, dan harga pasar.

3. Berdasarkan matriks SWOT diketahui bahwa pengembangan potensi HHBK dapat dilakukan dengan pemberian penyuluhan dan pelatihan untuk meningkatkan kreativitas Kashuri Wana Agung dalam mengelola, mengolah dan memasarkan produk HHBK. 


\section{DAFTAR PUSTAKA}

Arikunto, S. 2010. Prosedur Penelitian: Suatu Pendekatan Praktik. Buku. Rineka Cipta. Jakarta. 256p.

Banuwa, I. S., A. Setiawan, C. Wulandari, S. B. Yuwono, Z. Abidin, P. Budiono, K. Istanto, I. Affandi. 2013. Pengelolaan Hutan dan Daerah Aliran Sungai Berbasis Masyarakat: Pembelajaran dari Way Besai Lampung. Buku. Anugrah Utama Raharja. Lampung. 273 p.

Irawanti, S., A. P. Suka, S. Ekawati. 2012. Peranan kayu dan hasil bukan kayu dari hutan rakyat pada pemilikan lahan sempit : Kasus Kabupaten Pati. Jurnal Penelitian Sosial dan Ekonomi Kehutanan. 9(3) : 113-125p.

Masjud, Y. I. 2000. Kajian karakteristik dan dampak lingkungan kegiatan petani sekitar hutan. Thesis. Institut Pertanian Bogor. Bogor. 58p.

Nazir, M. 2005. Metode Penelitian. Buku. Ghalia Indonesia. Bogor. 544p.

Njurumana, G. N. D. dan T. Butarbutar. 2008. Prospek pengembangan hasil hutan bukan kayu berbasis agroforestri untuk peningkatan dan diversifikasi pendapatan masyarakat di Timor Barat. Info Hutan. V(1) : 53-62p.

Notoatmodjo, S. 2003. Pendidikan dan Perilaku Kesehatan. Buku. Rineka Cipta. Jakarta. $210 \mathrm{p}$.

Nugroho, A. C., T. M. Frans, R. P. Kainde, dan H. D.Walangitan. 2015. Kontribusi hasil hutan bukan kayu bagi masyarakat di sekitar kawasan hutan. Jurnal Cocos. 6(5):12p.

Nurrani, L. dan S. Tabba. 2013. Persepsi dan tingkat ketergantungan masyarakat terhadap sumberdaya alam Taman Nasional Aketajawe Lolobata di Propinsi Maluku Utara. Jurnal Penelitian Sosial dan Ekonomi Kehutanan. 10(1):61-73.

Rangkuti, F. 2014. Analisis SWOT: Teknik Membedah Kasus Bisnis (Reorientasi Konsep Perencanaan Strategis untuk Menghadapi Abad 21). Buku. PT.Gramedia Pustaka Utama. Jakarta. 246p.

Suharyat, Y. 2009. Hubungan antara sikap, minat, dan perilaku manusia. Jurnal Region. 1(2):19p.

Supadi dan A. R. Nurmanaf. 2006. Pemberdayaan petani kelapa dalam upaya peningkatan pendapatan. Jurnal Litbang Pertanian. 25 (1). 31-36

Susilowati, I. 2007. Evaluasi implementasi pengelolaan hutan bersama masyarakat (PHBM) Di Kph Randublatung Blora. Tugas Akhir. Universitas Diponegoro. Semarang.

Waluyo dan A. I. Sari. 2014. Penguatan ekonomi kreatif masyarakat lereng Merapi melalui peningkatan keterampilan dan produktivitas usaha. Jurnal Pertanian. 2(11):307-317.

Watala. 2009. Hutan Kemasyarakatan Melestarikan Hutan untuk Kesejahteraan Masyarakat (Catatan 10 Tahun Program HKm di Provinsi Lampung). Buku. Watala. Lampung. $122 \mathrm{p}$.

Wulandari, S. 2012. Pengaruh efikasi diri terhadap minat berwirausaha pada siswa kelas XII di SMK Negeri 1 Surabaya. Jurnal pendidikan tata niaga. Vol.1 No.1 :1-20 